\title{
Open-ended Practical Projects Improve Preparedness of Undergraduate Students for Aerospace Industry
}

\author{
Sergey Dubikovsky, Thomas A. Goodrich, Ronald Sterkenburg \\ Purdue University
}

\begin{abstract}
The Aviation Technology Department in the College of Technology at Purdue University has been effective at graduating students who have mastered the technical knowledge and concepts taught in traditional academic settings. Through a well-established combination of courses, the program has also exposed its students to a variety of materials and processes that gives them practical knowledge about aerospace materials, sheet metal fabrication and repair, corrosion, heat treatment, and painting. Over the years, this approach has provided graduates with the knowledge and skills they've needed as they entered the job market after graduation. However, in recent years the program has gone through an extensive curriculum change designed to produce graduates who have the skills needed to be immediately productive in entry-level positions, and to move quickly to higher-level positions. This is accomplished by introducing project-based courses in which students are tasked to solve industry-like problems using Six Sigma tools, work in teams, and collaboration with companies and with instructors and students at other universities. Under this new paradigm, students do not just follow their professors' instructions they attempt to solve real-world open-ended problems with a range of possible solutions. This paper will provide some details and outcomes of this approach.
\end{abstract}

\section{INTRODUCTION}

In today's more demanding job market, employers are seeking applicants who have developed the intellectual and physical skills needed to be immediately productive when they begin their new careers in industry. This requires not only the knowledge and skills that previous students have learned in traditional teaching contexts, but also practical experience, which can only be acquired by actually doing a job. As a result, American universities, in general, are adding more hands-on engineering projects to their curriculum to attract new students (Collicott, 1998). Most students are motivated by hands-on projects, which help sustain students' interest in technology and the curriculum, thereby preventing them from switching to other majors (Costlow, 2005).

Previous inquiries have looked at the development of curricula that were specifically-designed to implement an educational approach integrating the traditional delivery of knowledge with a program that develops student skills and provides practical experience in those same subject areas. The goal of the new curriculum is to help the graduates of the Aeronautical Engineering Technology program to be hired in entry-level engineering positions in areas such as liaison engineering, technical support, field engineering, supply chain and project engineering. It is also expected that graduates will move up into management and leadership positions within two to five years (Dubikovsky, Stanley, \& Wild, 2008). The mechanism for achieving these goals is the addition of two new courses to the curriculum: Aircraft Materials and Manufacturing Processes (AT308), and Advanced Manufacturing Processes in Aviation (AT408). At Purdue University, these courses have now been in place long enough that several classes of students have taken the courses and the content has been refined and polished. 


\section{COURSE STRUCTURE AND CONTENT}

AT308. Freshman aviation technology students are required to take required AT 108 and AT 166 courses. In these classes, students deal with, and get practical experience in working with, a variety of materials and processes, including aerospace materials, welding, sheet metal fabrication and repair, and corrosion, heat treatment, and painting. In these courses, students acquire, practice, and master basic skills that will be necessary in later courses.

AT308, which is the redesigned Aircraft Manufacturing course, is intended to take students to the next level by exposing them to additional topics like introduction to strength of materials, structural joint design, the use of CNC equipment, and quality-control systems such as ISO 9000. The course, however, goes well beyond merely offering additional course material; in this course, students are given work orders, as if they were employees of a company; this introduces them to the experience of using their new-found knowledge to accomplish a long-term goal (Dubikovsky, 2009).

Students work in teams, learning how to work together and how to handle disagreements or problems that may occur (Samuel, 2005). However, each one is still required to take personal responsibility for his or her individual work. Their manufacturing facility (the laboratory) is equipped with a variety of industrial tools including lathes, milling machines, testers, and other machining equipment. During the course of the semester, each student participates in an instructor-supervised project by filling a variety of different roles; for example, a student will most likely work as a machinist, a team leader, a quality control inspector, and in several other capacities over the fifteen-week period. By doing this, each student not only gets a variety of practical experience, but also sees how a project develops and how it looks from a variety of different perspectives. In the end, students learn how to follow instructions, understand logic and systems and the reasons and science behind them.

AT408. The logical continuation of this course of study is the newly-created Advanced Manufacturing course, which emphasizes design process and advanced materials manufacturing. Students in this final senior-level course have already developed basic aircraft materials skills from prerequisite coursework in the curriculum. In AT408, students integrate baseline technical skills with advanced problem-solving skills and processes involved in design and manufacture of more complex component parts, including aircraft components and assemblies which play a critical role in flight safety in industry. The course is entirely project-based, allowing students to perform research and to design products to specific requirements, which takes them through all the steps of the design process, starting with a requirement or need all the way to final assembly in just fifteen weeks (Billing, 2007; Kim, Kamoua, \& Pacelli, 20052006).

The students take their assigned responsibilities very seriously and work diligently to develop solutions to the tasks, in part because they are in charge in their own learning (Massa, 2008). Prior to this point in the curriculum students have learned to perform assigned duties, but have not created their own work guidelines or taken full responsibility for an entire project (Shakirova, 2007). This course allows students to take a project from the design stages through to completion, with the instructor performing the role of facilitator and supervising the independent work of the teams (Beringer, 2007). 


\section{EVALUATING THE EFFECTIVENESS OF THE PROGRAM}

Ultimately, of course, the most valid way to evaluate the effectiveness of such a program of study would be to see whether students with these more practical skills and actual experience are more likely to be hired and how well they succeed in the workplace. This will be an important subject for further study in the near future when such data become available.

In the meantime, however, one thing that researchers can look at is whether the students perceive value in this educational approach as they are going through the program. While it is true that student perceptions may not indicate whether the program is actually accomplishing what is intended, those perceptions do suggest whether students understand the value of the more practical approach and whether they are buying into it.

In order to get a preliminary look at how students perceive the value of their participation in the sequence of classes outlined above, students completing AT308 in the spring semester of 2009 were asked to respond to a six-question survey. In the fall semester of 2009, students completing AT408 were asked to complete the same survey. The class lists (and therefore the survey samples) were not identical because not all AT308 students chose to take AT408 in the fall semester of 2009, and one AT408 student had already taken AT308 during a semester prior to the spring of 2009. There were twenty-nine students in the survey sample for each semester; in the AT308 class, twenty-nine of thirty-six students completed the survey, and in the fall semester AT408 class, all 29 students in the class completed the survey. In any event, the sample of students was self-selecting in that they voluntarily signed up for the courses, either because of an individual interest in the subject matter or because the courses were required for their course of study. The relatively small sample size for the survey was the direct result of the size of the laboratory classes in which the survey was taken.

The survey was set up using a Likert Scale of five categories which asked students to select one of the following choices in response to each of the survey's six statements: "Strongly Disagree," "Disagree," "Neutral," "Agree," and "Strongly Agree." Survey questions one and four addressed student attitudes concerning structured vs. open-ended course organization and team working situations, while questions two, three, five and six assessed their attitudes concerning the course's approach to the acquisition and practical application of knowledge and skills. Because of the preliminary nature of the investigation, student surveys were intentionally kept short and to the point.

\section{SURVEY RESULTS}

\section{Structured vs. open-ended course organization and team working situations}

Question 1. Students were asked to respond to the following statement: "When given the choice, I would prefer to work on a highly-structured project that has an identifiable correct solution rather than work on an "open-ended" project where I must find a satisfactory solution to the problem."

In AT308, during the spring semester, forty-one percent of the students disagreed or strongly disagreed with this statement, indicating that they preferred the "project-oriented" assignment over the traditional

laboratory assignments. Twenty-eight percent had no opinion on the matter, and thirty-one percent preferred the structured situation. 
In the fall, after taking AT408, fifty-two percent of the students indicated a preference for projectoriented learning. This represents a more than twenty-five percent increase over those expressing that same opinion in the spring. While the uncommitted percentage remained the same at twenty-eight percent, those preferring the more structured assignments fell from thirty-one percent in the spring to twenty-one in the fall (see Figure 1).

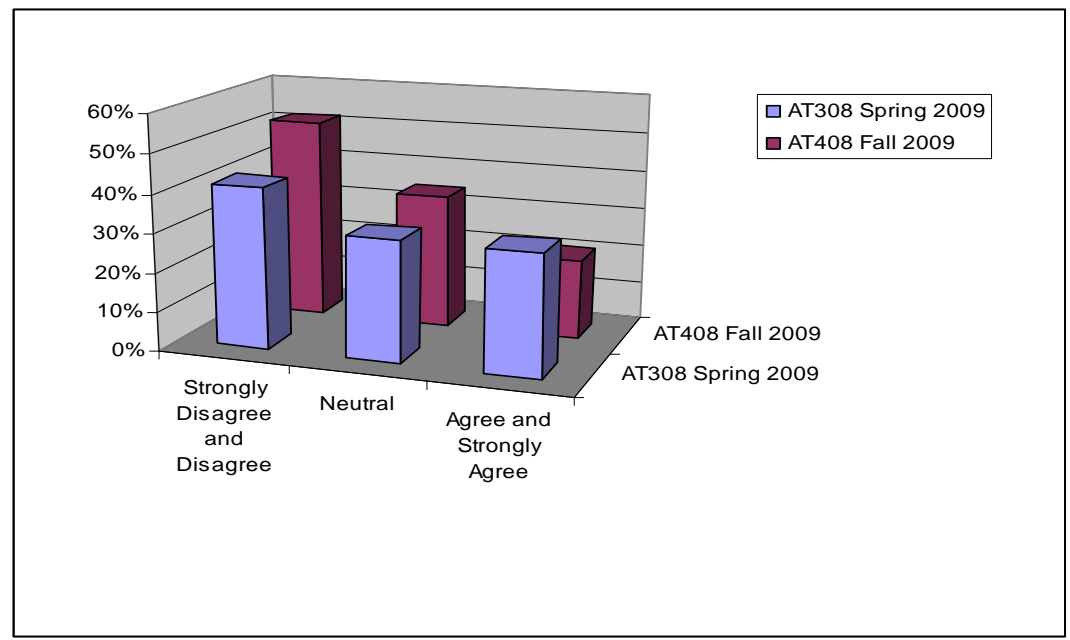

Figure 1. Answers for question 1 "When given the choice, I would prefer to work on a highly-structured project that has an identifiable correct solution rather than work on an "open-ended" project where I must find a satisfactory solution to the problem."

Question 4. Students were asked to respond to the following statement: "I think I might learn more in a laboratory situation if I didn't have to work with other students."

When AT308 students responded, forty-eight percent of them indicated that they disagreed or strongly disagreed with this statement. Twenty-four percent had no opinion, and twenty-eight percent agreed or strongly agreed with the statement. Sixty-nine percent of the AT408 students said that they disagreed or strongly disagreed with the statement, showing a forty-three percent increase in the number of students who felt they learned more in the laboratory setting when working with other students. The percentage of "no opinion" students went down to fourteen percent from twenty-four percent, and the pool of those still preferring to work by themselves dropped from twenty-four percent to seventeen percent (see Figure 2). 


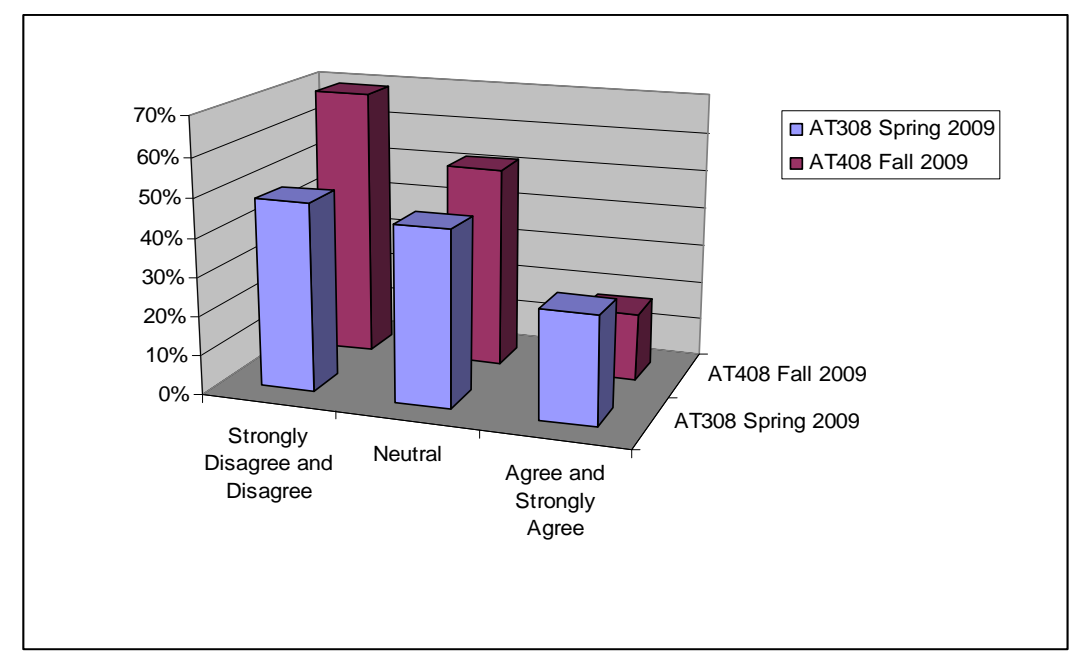

Figure 2. Answers for question 1 "I think I might learn more in a laboratory situation if I didn't have to work with other students."

\section{Acquisition and practical application of knowledge and skills}

Question 2. Students were asked to respond to the following statement: "I have found most of my laboratory assignments offer me a chance to put into practice what I have learned in my coursework."

During the spring semester, in AT308, ninety-three percent of the students agreed or strongly agreed with this statement, indicating that they saw the practical application of their classroom material in their laboratory assignments and were able to put it into practice. Three percent had no opinion on the matter, and three percent said the laboratory assignments did not give them a chance to put their knowledge into practice.

In the fall, after taking AT408, only seventy-nine percent of the students indicated that they saw the practical application of the material in their lab assignments. The uncommitted percentage rose to twentyone percent, and the percentage of students saying they saw no relationship between the classroom assignments and the lab assignments dropped to zero.

Question 3. Students were asked to respond to the following statement: "Sometimes I am not able to easily connect what I learned in class with the lab activities."

Forty-eight percent of the AT308 class disagreed with the statement, saying that they were able to connect what they had learned with lab activities. Twenty-eight percent had no opinion, and twenty-four percent agreed that they were not able to connect the classroom material with the lab material. When the same question was asked of the AT408 students, fifty-nine percent disagreed, which was a twenty-three percent increase over the responses to that question during the previous semester. The "no opinion" percentage stayed about the same at thirty-one percent, and the percentage of those who admitted to having trouble making the connections dropped to ten percent.

Question 5. Students were asked to respond to the following statement: "Having worked in project groups with other students, I believe I have developed important work skills that I didn't have before." 
During the spring semester, eighty-six percent of the AT308 students answered that they agreed that they had developed new skills; only seven percent had no opinion, and seven percent said they had not developed new skills. At the end of the fall semester, seventy-nine percent of the AT408 students said they had developed new skills; the percentage with no opinion remained constant, and the percentage of those who said they had not acquired new skills rose to fourteen percent.

Question 6. Students were asked to respond to the following statement: "Having had laboratory classes at Purdue, I have a greater appreciation of the practical application of the things I've been learning in my classes."

When the spring semester AT308 class responded, ninety-seven percent agreed that they had a greater appreciation of the practical applications of their course materials. Only three percent had no opinion, and no students disagreed. When the fall semester AT408 class took the survey, ninety percent said they had a greater appreciation of the practical applications of their course materials. Ten percent had no opinion, and no students disagreed with the statement.

\section{INTERPRETING THE RESULTS}

\section{Structured vs. Open-ended Course Organization}

In the first course of the two being reviewed, a large minority of students preferred the nontraditional, hands-on approach to the laboratory assignments over the typical highly-structured approach. When the same question was asked of students in the second course, the percentage of those preferring the new approach went up ten percent, and those holding that opinion were now in the majority (Question 1). It appears that students recognize that the less-formally-structured approach provided an additional value to the course; that value may have been interpreted by students as being another dimension of learning, or it could just be that they found the activity more interesting or engaging. Either way, students expressed a clear and growing preference.

\section{Working With Teams}

In this case, the results show not only a substantial increase in the percentage of students who did not object to working with others in a team learning and work situation, but also a ten percent reduction in the group with no opinion and a ten percent reduction in those who stated that they would prefer not to work with others in teams (Question 4). This across-the-board shift suggests both that students may be developing cooperative interpersonal skills, but that they were beginning to understand the organizational advantages of working with others. If either or both of these are the case, then students with this experience have the potential to be effective in a work environment much faster than those without that experience.

\section{The Acquisition and Practical Application of Skills}

In this area, students taking the two courses seem to believe that they have an increasing ability to connect what they learn in the classroom with the activities of the laboratory and the work world (Question 3). The ability to make and use those connections is the first and essential step in making an education practical; without the ability to apply what one knows, no amount of abstract knowledge is helpful to a potential employer. Having made those connections, a large majority of the students surveyed 
believe that they have developed important work skills. While a few more in AT408 say they have not learned new skills (fourteen percent, up from seven percent), the reason for this may very well be that the focus of AT408 shifts much of the emphasis to the planning, organizing, and project management skills necessary to bring the whole project to completion (Question 5). The same reasoning may account for the slight fall (from AT308 to AT408) in the percentage of students who recognize the lab assignments as an opportunity to put their classroom knowledge into practice (Question 2). Having said this, students in both classes responded in very high numbers (ninety-three percent in AT308, and seventy-nine percent in AT408) that the assignments did offer the opportunity to apply what they had learned. Finally, most students in both classes (ninety-seven percent in AT308 and ninety percent in AT408) said they had a greater appreciation of the practical applications of the classroom material (Question 6). At least from the perspective of the students, this means that the new approach to laboratory assignments has been successful. 


\section{REFERENCES}

Beringer, J. (2007, September). Application of Problem Based Learning through Research Investigation. Journal of Geography in Higher Education, 31(3), 445-457.

Billing, D. (2007, April). Teaching for Transfer of Core/Key Skills in Higher Education: Cognitive Skills. Higher Education: The International Journal of Higher Education and Educational Planning, 53(4), 483-516.

Collicott, S. H. (1998). Increasing freshmen experience in, and awareness of, aerospace engineering at Purdue University. AIAA Paper 98-0821, Aerospace Sciences Meeting.

Costlow, T. (2005, December 5). Projects Pose Grand Challenge. Design News, 60(18), 39-41.

Dubikovsky, S., Stanley, D., \& Wild, T. (2008). The Importance of Introducing New and Advanced Materials in Technology Education. ATEC Journal, 30(1), 27-35.

Dubikovsky, S. (2009). AT308, Inc. Trainee (Student) Orientation Manual (Syllabus). West Lafayette, IN: Purdue University.

Kim, D., Kamoua, R., \& Pacelli, A. (2005-2006). Design-Oriented Introduction of Nanotechnology into the Electrical and Computer Engineering Curriculum. Journal of Educational Technology Systems, 34(2), 155-164.

Massa, N. M. (2008, Winter). Problem-Based Learning (PBL): A Real-World Antidote to the Standards and Testing Regime. New England Journal of Higher Education, 22(4), 19-20.

Samuel, L. (2005, February). Communication Skills Are Keu (i.e. Key) to Career Success. Water Environment \& Technology, 17(2), 72.

Shakirova, D. M. (2007, September). Technology for the Shaping of College Students' and UpperGrade Students' Critical Thinking. Russian Education \& Society, 49(9), 42-52. 